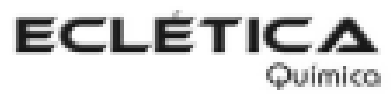

www.scielo.br/eq

Volume 29, número 1, 2004

\title{
Mobilidade conformacional de complexos entre calix[4]arenos e aminas: evidências para estruturas exo-calix
}

\author{
F. F. Nachtigall ${ }^{1}$, F. Nome ${ }^{2}$, M. Lazzarotto ${ }^{3 *}$ \\ ${ }^{4}$ Departamento de Química - Universidade Estadual de Ponta Grossa - CEP 84030-900 - Ponta Grossa- PR - Brasil. \\ ${ }^{2}$ Departamento de Química - Universidade Federal de Santa Catarina, C.P. 476 - Campus Trindade - CEP 88049-970 - \\ Florianópolis- SC-Brasil. \\ ${ }^{3}$ Departamento de Química Orgânica- Universidade Federal do Rio Grande do Sul - CEP 91501-970 Caixa Postal 15003 - \\ Campus do Vale - Porto Alegre - Rio Grande do Sul-Brasil.
}

Resumo: Os espectros de RMN de sais de calix[4]areno e aminas alifáticas , em acetonitrila, mostraram valores de deslocamento químico dos hidrogênios do calix[4]areno próximos entre si para as diversas aminas. Foram obtidas as temperaturas de coalescência $\left(t_{c}\right)$, acompanhando os hidrogênios metilênicos entre 32 e $38{ }^{\circ} \mathrm{C}$ para os sais de calixareno com as aminas e o aumento de $\mathrm{t}_{\mathrm{c}}$ deve-se ao aumento da basicidade da amina e não a fatores relacionados com o volume. Os dados estão de acordo com uma proposta exo-cálix, em que os cátions amônio situam-se fora da cavidade do calixareno.

Palavras-chave: calixarenos, complexos moleculares, cátions amônio

\section{Introdução}

Receptores moleculares para íons e moléculas neutras usualmente apresentam uma superfície côncava, com grupos aptos para a interação com os substratos, onde a complementaridade espacial tem uma função importante para aumentar as constantes de ligação.[1] Porém, muitas vezes fatores dinâmicos, tais como a dessolvatação na complexação, e restrição na mobilidade do receptor e substrato, não são adequadamente considerados para explicar fatores relacionados à magnitude e seletividade da formação do complexo[2].

Entre as moléculas sintéticas que são candidatas a receptores côncavos, citamos éterescoroa, ciclodextrinas e calixarenos, com grupos adequadamente posicionados para interagir através da interação com elétrons não-ligantes (ex.: éteres-coroa e íons metálicos), ligações de hidrogênio e interações hidrofóbicas.

Os calixarenos são oligômeros fenólicos cíclicos, com 4 a 14 unidades ligadas, sendo que os mais estudados são os calix[4]arenos, pelas suas características de semi-rigidez da cavidade, o que permite modular melhor a forma do receptor em solução[3].

A estrutura do calix[4]areno em solução assemelha-se a um cone truncado, com o quatro grupos $\mathrm{OH}$ fenólicos de um mesmo lado, interagindo através de ligações de hidrogênio intramoleculares. Além disso, quando ocorre a desprotonação do calixareno, o fenolato é estabilizado por ligações de hidrogênio, o que estabiliza o ânion e aumenta as constantes de acidez, tornando cerca de $10^{6}$ vezes mais ácido que os fenóis correspondentes. Esta propriedade permite os calixarenos atuem como ácidos de Brönsted em relação a aminas, levando à formação de íons amônio e os oxi-ânions dos calixarenos, que podem ser utilizados na construção de sensores seletivos para aminas. [4]

A estrutura destes complexos está sob in-

*Autor para correspondência: marcio@iq.ufrgs.br 
vestigação, com propostas para a formação de complexos endo-cálix ,[5,6] em que o amônio se situa dentro da cavidade do calixareno, ou exo-cálix, [7] em que o amônio se situa fora da cavidade do calixareno, interagindo por ligações de hidrogênio com os grupos $\mathrm{OH}$. Uma das formas de investigação da estrutura dos complexos é a observação dos sinais metilênicos axiais e equatoriais, cuja temperatura de coalescência está relacionada com a velocidade de conversão entre as formas cone.[8]

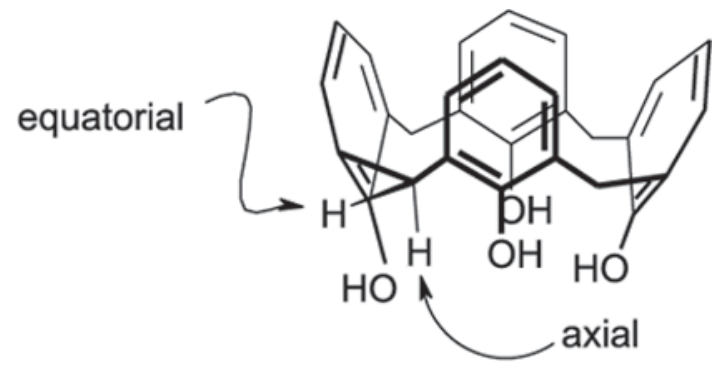

Esquema 1 - Calix[4]areno

\section{Procedimento Experimental}

Calix[4]areno foi obtido a partir da desbutilação do $p$-terc-butilcalix[4]areno, conforme método descrito na literatura. [9] As aminas utilizadas foram adquiridas de Aldrich e Sigma, e mantidas sobre peneira molecular $4 \AA$. Os espectros foram obtidos em várias temperaturas em um espectrômetro de Ressonância Nuclear Magnética BRUKER-AC $200 \mathrm{mHz}$, usando TMS como referência interna. A acetonitrila- $d^{3}$ usada nos espectros de RMN foi aberta no momento da preparação da amostra para análise de ampolas de $1 \mathrm{~mL}$ para diminuir a presença de água em solução. Os valores de deslocamento químico estão em $\delta$.

\section{Resultados e discussão}

Em acetonitrila, o movimento de inversão do cone do calix[4]areno é mais rápido que a escala de $\mathrm{RMN}$ ( $\sim 0,1 \mathrm{~s}$ ), e os sinais referentes aos hidrogênios axiais e equatoriais do calix[4]areno não podem ser distinguidos. A adição de aminas à solução do calix[4]areno em $\mathrm{CD}_{3} \mathrm{CN}$ leva à formação do sal e à definição destes sinais a $25 \mathrm{C}$, e torna-se possível visualizar o sinal correspondente ao hidrogênio axial (mais blindado, valores de $\delta$ menores) e equatorial, com diferença de cerca de 1 ppm entre ambos sinais.

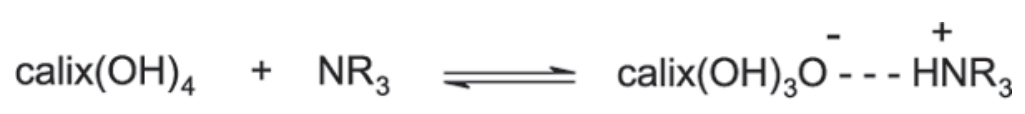

Esquema 2 - Equilíbrio entre calix[4]areno e amina

Os sinais dos hidrogênios aromáticos sofrem uma pequena blindagem $(\Delta \delta=0,2)$ com a desprotonação, e não é possível a distinção entre a unidade fenólica desprotonada e não-desprotonada, o que evidencia o rápido equilíbrio de troca de hidrogênio interna. Os $\delta$ dos hidrogênios aromáticos e metilênicos dos calixarenos praticamente não variam para as diferentes aminas estudadas. Contudo, a blindagem do hidrogênio axial e desblindagem do hidrogênio equatorial do calixareno no sal com terc-butilamina em relação às outras aminas primárias é uma indicação de um menor paralelismo entre o hidrogênio axial e os oxigênios fenólicos, isto é, $\mathrm{H}_{\mathrm{ax}}$ e $\mathrm{H}_{\mathrm{eq}}$ estão em am- 
biente químico mais parecido, com o cone mais aberto. Em geral, menor diferença entre os $\Delta \delta$ de $\mathrm{H}_{\mathrm{ax}}$ e $\mathrm{H}_{\mathrm{eq}}$ indica menor paralelismo entre os anéis benzênicos. As aminas que provocam as maiores $\Delta \delta$ foram a dietilamina e trietilamina, nestes casos os anéis benzênicos estão em posição mais paralela, isto é, o cone está mais fechado, o que reforça a proposta de complexos exo-cálix. Para a morfolina, não foi observada diferença entre os valores de deslocamento químico entre os hidrogênios endo e exo, pela fraca basicidade da amina, cujo grau de transferência de hidrogênio do calixareno é menor do que as outras aminas. Na tabela 1 estão os valores de deslocamento químico dos hidrogênios do calixareno na presença de aminas.

Tabela 1- Valores de deslocamento químico do calix[4]areno na presença de aminas

\begin{tabular}{|c|c|c|c|c|}
\hline amina & $\mathrm{H}_{\mathrm{ax}}$ & $\mathrm{H}_{\mathrm{eq}}$ & $\mathrm{H}_{\mathrm{m}}$ & $\mathrm{H}_{\mathrm{p}}$ \\
\hline hexilamina & 4,28 & 3,32 & 6,97 & 6,51 \\
\hline iso-propilamina & 4,28 & 3,33 & 6,97 & 6,50 \\
\hline terc-butilamina & 4,23 & 3,40 & 6,98 & 6,52 \\
\hline morfolina & $3,81^{a}$ & $3,81^{a}$ & 6,99 & 6,53 \\
\hline piperazina & 4,24 & 3,30 & 6,97 & 6,51 \\
\hline piperidina & 4,30 & 3,33 & 6,96 & 6,48 \\
\hline dietilamina & 4,33 & 3,31 & 6,97 & 6,50 \\
\hline trietilamina & 4,33 & 3,31 & 6,96 & 6,48 \\
\hline
\end{tabular}

a) apenas um valor de $\delta$ para os hidrogênios metilênicos foi observado.

O sinal do hidrogênio correspondente ao hidrogênio fenólico passa de d 11,0 para abaixo de d 9,0, dependendo da amina utilizada, o que está de acordo com um processo de troca intermolecular de hidrogênio entre o calixareno e o cátion amônio, porém estes valores não fornecem muita informação, pelo excesso de amina e presença de pequenas quantidades de água, que deslocam os sinais para freqüências mais baixas.

A inversão do cone do calix[4]areno se dá pela passagem pelo centro do calixareno de uma das unidades fenólicas, e depois ocorre o movimento das duas unidades vizinhas, e por fim, ocorre a passagem da última. Este processo depende do volume do grupo ligado ao átomo de oxigênio. No caso de grupos metil ou etil, ocorre um aumento na temperatura em que ocorre esta passagem, e no caso de grupos propil, a inversão é bloqueada, porque não existe espaço interno para a passagem da propila pelo centro da cavidade.[3]

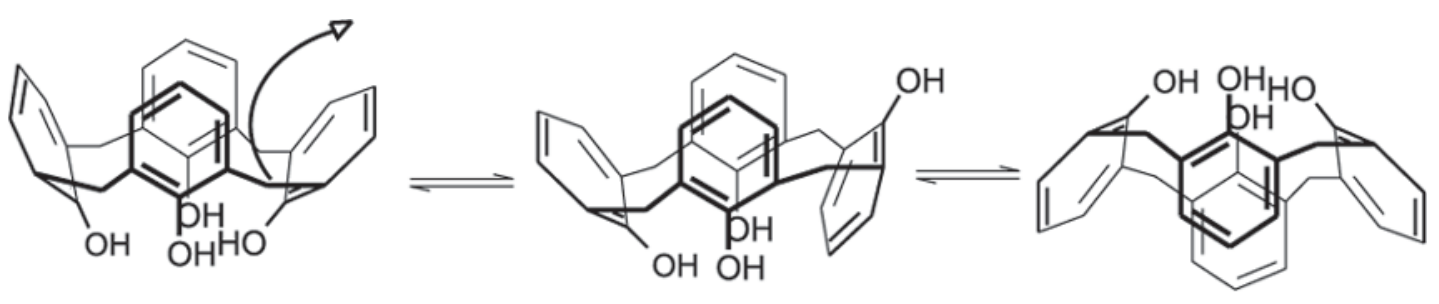

Esquema 3 - Movimento de inversão de configuração 
A diminuição da mobilidade conformacional pode ser atribuída a dois fatores: aumento da interação entre as hidroxilas fenólicas, mantendo o calixareno na conformação cone e o fenolato devido a desprotonação ou inclusão da amina, o que dificultaria o movimento dos átomos. Neste caso, para que a inversão ocorresse seria necessária a saída da amina da cavidade seguida do movi- mento. Este segundo fator seria importante caso houvesse a formação do sal endo, e aminas mais volumosas levariam a menor valor de temperatura de coalescência, que é a temperatura em que os sinais referentes aos hidrogênios axiais e equatoriais aparecem como um único sinal, uma vez que a inversão se dá em um tempo menor do que o tempo do RMN.

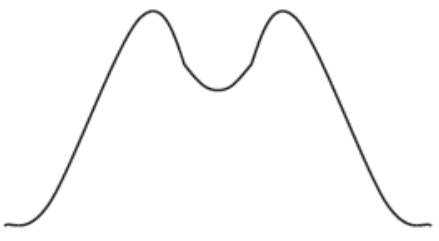

$\mathrm{t}<\mathrm{t}_{\mathrm{c}}$

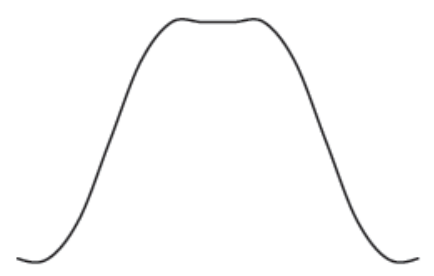

$\mathrm{t}=\mathrm{t}_{\mathrm{c}}$

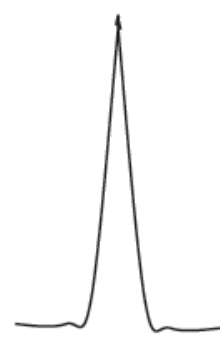

$\mathrm{t}>\mathrm{t}_{\mathrm{c}}$

Esquema 4 - Alteração do perfil de RMN de ${ }^{1} \mathrm{H}$ com a temperatura.

Os dados de temperatura de coalescência obtidos para diversas aminas estão sumarizados na tabela 2:

Tabela 2 - Temperatura de coalescência dos hidrogênios metilênicos do calix[4]areno na presença de aminas

\begin{tabular}{|c|c|}
\hline Amina & Temperatura de coalescência $\left({ }^{\circ} \mathrm{C}\right)$ \\
\hline hexilamina & 33 \\
\hline iso-propilamina & 33 \\
\hline terc-butilamina & 33 \\
\hline piperazina & 32 \\
\hline piperazina & 38 \\
\hline dietilamina & 37 \\
\hline trietilamina & 35 \\
\hline
\end{tabular}

A análise dos valores obtidos para $t_{c}$ revela que as variações foram pequenas para as diferentes aminas, e são adequadas com uma estrutura de sal exo de amônio e calixareno, uma vez que para complexos endo seriam esperados efeitos importantes tanto nos valores de deslocamento químico dos hidrogênios do calix[4]areno quanto nos valores de temperatura de coalescência. 
As pequenas variações de $t_{c}$ devem-se às diferentes interações entre calixarenos e aminas fazendo com que haja pequenas variações de $t_{c} d e$ acordo com a amina utilizada. Podemos atribuir a dois fatores principais as diferenças de valores de $\mathrm{t}_{\mathrm{c}}$ : a) quanto mais básica a amina, [10] maior a extensão de transferência de hidrogênio e maior $\mathrm{t}_{\mathrm{c}}$, e isto pode ser observado na tabela, com os maiores valores para a piperidina e dietilamina, enquanto que a piperazina, que é a menos básica, tem o menor valor de $\left.t_{c}, b\right)$ o aumento da capacidade e formação de ligações de hidrogênio pelo íon amônio tende a diminuir o valor de $t_{c}$, uma vez que as interações com o amônio desestabilizam as ligações intramoleculares do calixarenato, facilitando a inversão do cone. Porém, a atração eletrostática entre os íons calixarenato e amônio contribui para a fixação da estrutura. Assim, os cátions amônio que possuem três hidrogênios disponíveis (formados a partir de aminas primárias ) produzem os menores valores de $t_{c}$ e os amônios com dois hidrogênios ( formados a partir de aminas secundárias ) produzem os valores mais altos, com exceção da piperazina, já explicado anteriormente. A trietilamina que por este parâmetro deveria provocar o maior valor de $t_{c}$ apresenta um valor intermediário, pois possui carga mais dispersa, reduzindo o efeito eletrostático.

\section{Conclusão}

Os dados de deslocamento químico e de temperatura de coalescência confirmam a formação de sais com estrutura exo-cálix do cátion amônio em relação à cavidade do calix[4]areno, e que a interação entre o calixarenato e o íon amônio se dá pela formação de ligações de hidrogênio entre as hidroxilas fenólicas e o $\mathrm{H}-\mathrm{N}^{+}$do amônio.

\section{Agradecimentos}

CAPES, CNPq, CT-Petro Proc. 472413/015 e RENAMI ( Rede de Nanotecnologia Molecular e de Interfaces)

F. F. Nachtigall, F. Nome, M. Lazzarotto. M. Conformational mobility of complexes of calix[4]arene and amines: evidences for exo-calix structures.

\begin{abstract}
The NMR spectra of salts formed from calix[4]arene and aliphatic amines in $\mathrm{CD}_{3} \mathrm{CN}$ are in agreement with a exo-calix position of the ammonium cation. The chemical shifts (d) of aromatic and methylenic hydrogens of calix[4]arene were almost the same for the amines utilized. The coalescence temperatures $\left(\mathrm{t}_{\mathrm{c}}\right)$ were obtained and fall in the range between 32 and $38{ }^{\circ} \mathrm{C}$, and is higher for more basic amines, and was not observed dependence with the shape of the amine.
\end{abstract}

Keywords: calixarenes, molecular complexes, ammonium cations.

\section{Referências}

[1] A. Casnati, F. Sansone, R. Ungaro, Acc. Chem. Res. 36 (2003) 246.

[2] A. F D. De Namor, R. M. Cleverley, M. L. Zapata-Ormachea, Chem. Rev. 98 (1998) 2495.

[3] M. Lazzarotto, F. F. Nachtigall, F. Nome, Quím. Nova 18 (1995) 444.

[4] F. F. Nachtigall, I. Vencato, M. Lazzarotto, F. Nome, Acta Cryst. C 54 (1998) 1007.
[5] Q. Y. Zheng, C. F. Chen, Z. T. Huang, J. Incl. Phenom. Macrocycl. Chem. 45 (2003) 27.

[6] C. D. Gutsche, M. Iqbal, I. Alam, J. Am. Chem. Soc. 109 (1987) 4314

[7] P. Thuery, Z. Asfari, M.Nierlich, J. Vicens, Acta Crystallogr. Sect. C-Cryst. Struct. Commun. 58 (2002) 223.

[8]. F. F. Nachtigall, M. Lazzarotto, F. Nome, J. Braz. Chem. Soc.13 (2002) 295.

[9] C. D. Gutsche, L. Bauer, J. Am. Chem. Soc. 107 (1985) 6052.

[10] K. Izutsu, Chemical Data Series, IUPAC, Oxford, 1990, n. 35. 